\title{
Controvérsias da estratégia
}

o longo das últimas duas décadas, os debates em torno do que é estratégia tornaram-se cada vez mais acalorados e críticos. Esteartigo, iniciado com a descrição deum encontro imaginário entreas maioresautoridades mundiaisem estratégia empresarial, avança em direção aum balanço didático e panorâmico dos principais pontos de vista sobre estratégia. Em específico, sobre a natureza formal ou emergente da estratégia; sobre sua origem, se interna ou externaà empresa; $\mathrm{e}$ sobre a finalidade suprema desta última, se a maximização do valor ao acionista ou a extensão do valor a todos seus envolvidos.

\section{por Fábio Luiz Mariotto FGVEAESP}

0 velho Igor foi o primeiro a chegar ao $\mathrm{H}$ arvest, o elegante restaurante de Cambridge, perto do campus de H arvard. 0 maître conduziu-o ao pátio, ao ar livre, onde o grupo tinha reservad o uma mesa para seis. 0 lugar era charmoso e o tempo estava agradável naquela noite do verão de 1992. Igor sentou-se à mesa, pediu ao garçom uma "M oscow mule" e beliscou o antepasto. Não demorou muito e chegou um segundo conviva, Henry, um cinqüentão vigoroso.

- Olá, Igor! Fico feliz em vê-lo - saudou Henry. 
I gor havia se levantado para cumprimentar o recémchegado, mas ol hava-o com certa hesitação.

- Boa noite, Henry - respondeu Igor, com cortesia cerimoniosa. Sentaram-se e Henry continuou:

- Considero um privilégio poder estar com você neste jantar. Você sabe como eu o admiro. Eu ainda era um jovem estudante quando você já era famoso. - Fez uma breve pausa e encarou o companheiro. - Você parece não acreditar que estou sendo sincero, I gor. $\mathrm{N}$ ão me diga que ainda está magoado com nossa troca de artigos no Strategic M anagement J ournal, está?

- Não, não estou - respondeu o outro, calmo, mas com firmeza. Henry continuou:

- Se discordamos em algumas idéias, isto não quer dizer que não respeito as suas...

- Claro, entendo isto - respondeu Igor, ajeitando a armação grossa e negra dos óculos. - Só achei que sua reação às minhas críticas foram um tanto contundentes. dos, e você quer equilibrá-la, você põe todo o peso no outro extremo, e não no meio, concorda?

- Concordo, mas suas críticas também revelam alguns preconceitos seus. Por exemplo, você não acredita na capacidade do ser humano em ser racional.

- Eu não acredito no poder do formalismo, Igor. A gente só consegue formalizar aquilo que já está definido, cristalizado. Portanto, ao formal izar um procedimento, a gente impede que algo realmente novo - uma estratégia inovadora - brote do processo.

- Mas um processo formal não precisa ser inflexível, Henry. Ele pode incorporar flexibilidades para permitir avaliação de resultados e correção de curso.

- Para mim, "planejamento estratégico flexível" é uma contradição em termos - sentenciou Henry.

- Seu entendimento do que é planejamento estratégico parece que ficou congelado em 1965, quando publiquei Corporate Strategy. A versão original de planejamento estratégico, que expus nesse livro, já não é mais praticada pelas organizações. Vocêse fixou nessa versão e não leva em conta tudo o que eu escrevi depois, corrigindo as deficiências da visão original. Entre outros aperfeiçoamentos, incluí ferramentas para a resposta estratégica da empresa a novas circunstâncias, em tempo real.

Henry teve vontade de argumentar que foi I gor quem primeiro adotou um tom agressivo na sua crítica, mas conteve-se:

- Olhe, Igor, reconheço que tenho escrito críticas inflamadas ao planejamento estratégico, e o tom dos meus argumentos pode dar a impressão de que eu descarto 0 planejamento como uma ferramenta gerencial útil para as organizações. Eu exagerei de propósito minhas críticas para que o debate sobre essa técnica pudesse se dar num terreno mais neutro. Considerando-se a enorme popularidade do planejamento estratégico e a confiança arraigada que as pessoas têm no poder desse método, se eu não enfatizasse as suas deficiências e as suas fraquezas eu não conseguiria criar interesse por alternativas. É como numa gangorra: quando só há uma pessoa, sentada num dos la-
- Bem - comentou Henry, - minha crítica ao planejamento estratégico é dirigida ao processo que você descreveu originalmente. Foi essa concepção que ganhou grande popularidade e se estabeleceu como modelo. Vocêpode ter incorporado aperfeiçoamentos nessa concepção ao longo do tempo, mas o model o original já se tinha estabelecido, com sua inflexibilidade e incapacidade de adaptação.

- Olhe, Henry, decisões estratégicas têm que ser tomadas, mesmo quando há incerteza, e o método que proponho ajuda o gestor a reduzir a incerteza e a enfrentá-la de forma racional e organizada. 0 modelo que você defende, e que chama de "estratégia como um processo de aprendizagem", só pode ser usado em decisões estratégicas incrementais, de efeitos pequenos, do contrário, a organização teria que esperar al gum tempo até poder obser- 
var os resultados e aprender com eles. Correria riscos grandes demais. Para decisões estratégicas que não sejam incrementais, o planejamento é indispensável. Tome um exemplo simples: como uma empresa vai tomar uma decisão de construir uma nova fábrica sem uma sistemática análise prévia do ambiente externo, dos seus recursos e das suas opções estratégicas?

Henry ia responder, mas, nisso, dois outros convivas estavam chegando à mesa, Jay e Jean. Eram os mais jovens do grupo, beirando os quarenta: o primeiro, rechonchudo e bonachão; o segundo, magro e sisudo.

- Olá, rapazes! - saudou Jay. - Vocês ainda estão discutindo planejamento estratégico? Está na hora de chegarem a um acordo! - Disse isto enquanto ele e Jean iam cumprimentando os outros dois comensais. Jay apresentou Jean a I gor, que não o conhecia pessoalmente. Os dois recém-chegados se acomodaram nas suas cadeiras e pediram drinques.

Ainda faltavam dois membros do grupo. Dalí a alguns minutos, eles chegaram juntos ao pátio. Henry saudou-os:

- Ora, vejam quem está chegando, a dupla de Harvard! Olá, Mike, olá, Mike! - Eram dois xarás, um loiro, com ar um tanto arrogante, o outro moreno e mais simpático.

Após os cumprimentos, todos se acomodaram à mesa. Jay retomou a palavra, dirigindo-se aos dois recém-chegados.

- Estavam os dois aqui debatendo sobre planejamento estratégico - e indicou Igor e Henry com um gesto da cabeça. 0 Michael loiro comentou em tom jocoso:

- Henry adora colocar idéias e pensadores em escaninhos para depois poder deliciar-se em criticá-los um a um. Ele já falou o diabo das minhas teorias e até criou um escaninho para elas, que ele chamou de "Escola do Posicionamento". - Virou-se para Jay. - Você também tem críticas às minhas teorias, não é verdade, Jay?

Henry parou de sorver um gole do seu drinque para avisar:

- Olhem, eu já polemizei o suficiente por hoje. Vou me abster de comentar.

Jay tomou a palavra, respondendo a Michael:

- Mike, acho que todos nesta mesa reconhecem que você foi um pioneiro no esforço de se entender as fontes de vantagem competitiva das empresas. Até a publicação do seu modelo das cinco forças da concorrência, a identificação das fontes de vantagem competitiva que estavam fora da empresa carecia de uma estrutura conceitual. 0 model o das cinco forças forneceu essa estrutura, e os estudiosos de estratégia Ihe são gratos por isso. 0 problema é que seu modelo era tão novo e tão rico em recursos de análise que ele veio a dominar a análise estratégica. E esse enfoque em forças externas à firma, embora valioso, era incompleto. Ele acabou desviando a atenção dos analistas deforças internas que, no meu entender, são tanto ou mais importantes para a competitividade duradoura da firma quanto as pressões competitivas atuantes em um dado ramo de negócios.

- Reconheço que há elementos internos importantes respondeu Mike. - Tanto é que os conceitos de "cadeia de valor" "e "sistema de atividades", que eu desenvolvi posteriormente, referem-se a características internas da empresa.

- Ainda assim, você nunca reviu o pressuposto do seu model o da concorrência, de que as firmas de um mesmo ramo são idênticas no que se refere aos recursos que elas controlam. Pois, a meu ver, são exatamente as desigual dades entre as firmas na dotação de recursos e no acesso a fatores de produção diferenciados que explicam a vantagem competitiva de algumas delas.

0 garçom esperava pacientemente, lápis e bloquinho em mãos, para anotar os pedidos. Os convivas interromperam momentaneamente a discussão para escolher os pratos. Feitas as escolhas, Jean tomou a palavra.

- Vocês já apresentaram duas questões polêmicas na teoria da estratégia empresarial, começou Jean. Pois bem, permitam-me introduzir mais uma: é a questão da teoria das partes interessadas (stakeholder theory). Suponho que todos aqui estejam familiarizados com essa teoria; ela defende que a empresa deve ter por objetivo atender aos interesses de todas as principais partes envolvidas nas ações da empresa, incluindo, além dos acionistas, os empregados, os clientes, os fornecedores, a comunidade e o governo. É uma proposta que contrasta com a visão atual predominante, segundo a qual a empresa deve buscar a maximização do valor para os acionistas. 0 encaminhamento desta questão pode vir a transformar a empresa capitalista como ela é hoje.

- Não é uma idéia nova - comentou Igor. - Há qua- 
renta anos, Frank W. Abrams, presidente da Standard Oil de New Jersey, já divulgava a idéia de que os gestores de uma empresa têm o dever profissional de achar um equilíbrio harmonioso no atendimento dos interesses das várias partes interessadas. Pouco depois, Peter Drucker argumentou que esse equilíbrio era necessário para a sustentabilidade da empresa.

Michael (o outro) interveio:

- Como você sabe, Jean, eu defendo o que você chama de "visão atual", a maximização do valor para os acionistas. Minha posição não decorre de uma postura social, moral, ou ideológica, mas sim da consideração cuidadosa e imparcial das alternativas, que são claramente menos satisfatórias. Uma das alternativas, a stakeholder theory, está ganhando popularidade neste início de década. A idéia, como você disse, é que os gestores da empresa deveriam buscar satisfazer simultaneamente aos interesses de todas as partes interessadas. Evidentemente, é uma proposta muito atraente do ponto de vista social, o que explica uma parte da sua popularidade. Agora, notem que o objetivo da empresa que essa teoria propõe é mais complexo do que a maximização do valor para os acionistas e a busca de formas de atingir esse objetivo complexo dificultaria muito o trabalho dos gestores e dos conselheiros de empresas. Surpreendentemente, os gestores e os conselheiros apóiam entusiasticamente essa teoria. Q ue explicação você dá para este paradoxo, Jean?

cipais razões que tornam a stakeholder theory inaplicável na prática.

Jean argumentou:

- No entanto, a experiência das empresas do mundo real mostra que, mesmo em empresas que declaram ter como objetivo último a maximização do valor para o acionista, alguns administradores profissionais acabam dando prioridade aos seus projetos pessoais.

- É verdade. Para evitar essa distorção, temos que aprimorar os instrumentos de governança das empresas, a começar pelo Conselho deAdministração... - começou Michael.

- Perfeito! - interrompeu Jean. - Mas, se é assim, podemos pensar num passo além e desenvolver instrumentos que tornem viável a implementação prática da teoria das partes interessadas, já que ela atende a um interesse social mais amplo do que a maximização do valor para o acionista.

- Que instrumentos são esses? - desafiou Michael.

- Alguns ainda precisam ser desenvolvidos. Os avanços recentes no estudo econômico dos incentivos e dos contratos podem ajudar na concepção desses instrumentos.

0 garçom pediu licença para esclarecer alguns detaIhes sobre os pratos escolhidos...

Um debate real . A conversação relatada acima é, evidentemente, fictícia. 0 encontro descrito não aconteceu de fato, ao menos nas circunstâncias relatadas. Porém, os personagens são reais e os pontos de vista a ele atribuídos na narrativa foram, de fato, expressos por eles próprios em diferentes ocasiões e lugares. $\mathrm{Na}$ ordem, os personagens deste encontro imaginário são Igor Ansoff, mundialmente conhecido como o "pai da gestão estratégica" (falecido em 2002); Henry Mintzberg, pesquisador da McGill

- A teoria das partes interessadas dá a eles mais liberdade de servir aos seus interesses pessoais - respondeu Jean. - Eles podem sempre alegar que tomaram uma decisão para atender ao interesse de alguma das partes.

- Exatamente - disse Michael. - Esta é uma das prin-
University, de Montreal, conhecido por seu espírito crítico e por ter criado os conceitos de "estratégia emergente" e "estratégia como aprendizagem"; Michael Porter ("Michael loiro", na narrativa), da H arvard Business School, o mais conhecido "guru" deestratégia da atual idade; Michael Jensen (o outro Michael), da mesma escola, conhecida au- 
toridade em finanças corporativas; J ay Barney, da O hio State University, um dos expoentes da chamada "visão da firma baseada em recursos"; e Jean Tirole, diretor do Institut d'Économie Industrielle, de Toulouse, na França, conhecida autoridade em economia das organizações.

A conversa narrada é uma alegoria dos debates que se travavam sobre estratégia no início dos anos de 1990. Já a partir de meados da década de 1980, o estudo de estratégia começou a se tornar mais crítico. A análise estratégica, até então dominada por textos normativos, passou a incorporar estudos com base mais científica, apoiados na economia, na sociologia e em outras ciências humanas.

0 colóquio descrito acima é uma amostra das três maiores controvérsias que se debatiam na época: (1) As estratégias devem sair prontas de um processo de planejamento (Igor Ansoff) ou devem emergir de um processo de aprendizado (Henry M intzberg)? (2) A análise estratégica deve dar mais atenção ao posicionamento da empresa face à sua concorrência (M ichael Porter) ou aos recursos que ela possui ou controla (Jay Barney)? (3) De que forma a empresa serve melhor à sociedade: tendo por objetivo maximizar o seu valor para os acionistas (M ichael Jensen) ou tendo como objetivo atender aos interesses de todas as partes nela interessadas (J ean Tirole)?

Formalismo versus espontanei dade. Com relação ao dilema "planejamento versus aprendizagem", na década de 1980, o tradicional "planejamento estratégico" foi alvo de muitas críticas e vários analistas chegaram a culpar essa prática pela perda de competitividade dos Estados Unidos perante o Japão e outros países. As críticas culminaram no livro de Henry Mintzberg, A Ascensão e Queda do Planejamento Estratégico, publicado em 1994. Nesse livro, Mintzberg afirma que a prática do planejamento estratégico é incapaz de produzir estratégias inovadoras e que ela só é útil para programar estratégias já traçadas. A deficiência central do processo, segundo Mintzberg, é que ele não consegue gerar insights (novas compreensões) estratégicos relevantes.

A alternativa que Mintzberg propõe é um processo de aprendizado (ou seja, de tentativa e erro), no qual as estratégias vão sendo elaboradas à medi da que são execu-

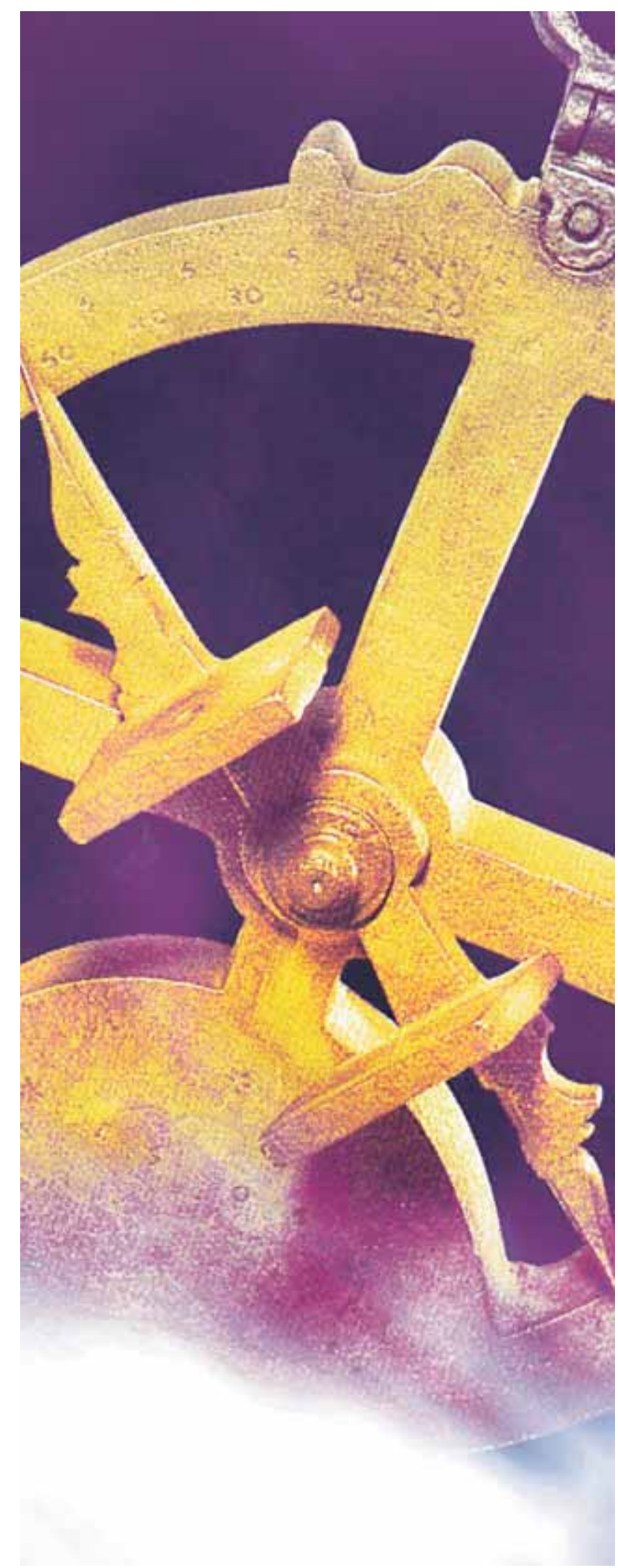


tadas. Em outras palavras, a reflexão e a ação estratégica passam a ser interativas e concomitantes. 0 próprio M intzberg reconhece que essa abordagem não é ad equada a qualquer tipo de organização ou a qualquer situação. Ela se presta mais a organizações como firmas de consultoria, organizações de pesquisa e desenvolvimento, agências de propaganda e outras, caracterizadas por sua estruturação em forma de projetos e organizad as primariamente em torno de especialistas.

Entretanto, os defensores do planejamento estratégico foram, ao longo dos anos, corrigindo suas fal has e tornando o processo mais flexível e adaptativo. Seus defensores reconheceram que a separação entre a formulação e a implementação da estratégia era uma deficiência importante da concepção original e que era necessária uma abordagem mais integrada dessas duas atividades. 0 próprio Igor Ansoff cunhou a expressão "gestão estratégica" para significar essa visão integrada e a expressão foi gradualmente substituindo "planejamento estratégico" na linguagem dos estrategistas.

Dentro versus fora. 0 segundo debate, 0 da importância relativa do "ambiente interno" da empresa em comparação com o seu "ambiente externo", acendeu-se no início dos anos de 1990. Em 1980, Michael Porter tinha revolucionado os estudos de estratégia, introduzindo idéias da análise econômica da concorrência. Esta era uma área da teoria econômica até então aplicada exclusivamente pelo governo para monitorar e inibir o abuso do poder de mercado e de outras práticas monopolizadoras das empresas. 0 modelo desenvolvido por Porter, apelidado de "modelo das cinco forças da concorrência", é um instrumento de análise sofisticado para a compreensão das pressões que vários agentes do mercado exercem sobre a lucratividade das empresas.

A contribuição de Porter foi tão revolucionária que essa visão passou quase que a dominar a reflexão estratégica, em detrimento da análise do "ambiente interno" da empresa. 0 próprio Porter tentou equilibrar sua proposta, introduzindo as idéias de "cadeia de valor" (1985) e de "sistema de atividades" (1996), perspectivas voltadas ao interior das empresas. Ao mesmo tempo, estudos econométricos mostravam que, na média, fatores internos à empresa explicavam mais a sua lucratividade do que 0 ambiente externo (mais precisamente, o ramo de negócios em que a empresa atuava). Isto levou, nos anos de 1990, a uma reval orização dos fatores internos à empresa, especialmente seus recursos, suas competências distintivas e sua cultura interna.

Um dos expoentes dessa visão baseada nos recursos da empresa foi Jay Barney. Entre outras vantagens dessa visão, al egava-se que esses fatores internos garantiam uma vantagem competitiva mais sustentável, no longo prazo, do que o posicionamento da empresa no seu mercado. 0 debate persiste até hoje, mas os consultores de estratégia resolvem o impasse de uma forma prática: analisam tanto os fatores externos quanto os internos e definem o peso de cada âmbito caso a caso.

A fi nali dade da empresa. Final mente, o terceiro dilema que aparece na conversa narrada acima, o do "shareholders versus stakeholders", refere-se ao objetivo último da empresa: este deve ser o de maximizar o valor da empresa para os acionistas ou o de atender aos interesses de todos os que são afetados pelas ações da empresa? Talvez esta seja a questão mais importante de gestão empresarial na atualidade. Em última instância, ela trata da modalidade de capital ismo que se deseja adotar (e que talvez ainda não tenha sido desenvolvida).

$\mathrm{Na}$ conversa narrada anteriormente, Michael Jensen figura como defensor da visão dos shareholders; J ean Tirole defende que haja mais pesquisa para se desenvolver mecanismos contratuais e/ou incentivos, de forma a tornar a visão dos stakeholders economicamente mais eficiente, inclusive respondendo às objeções respeitáveis de Jensen. Esta discussão tem se sofisticado nos últimos anos, mas ainda há muito a ser analisado, observado, desenvolvido e avaliado. É um dos assuntos do momento, mas teremos muitos anos pela frente antes que soluções mais claras e validadas na prática estejam disponíveis.

\section{Fábio Luiz Mariotto}

Prof. Titular do Departamento de Administração Geral e Recursos Humanos da FGV-EAESP

Ph.D. em Filosofia pela Escola Graduada de N egócios da Universidade de Stanford

E-mail: fmariotto@fgvsp.br 